\title{
ASPECTOS MORFO-HISTOLÓGICOS E FUNCIONAIS DO SISTEMA URINÁRIO DO SAPO, Rhinella schneideri (Werner, 1894) EM ESTRESSE HÍDRICO
}

SANTANA, Kleber, Luis ${ }^{1}$

SILVA, Thiago Borges ${ }^{1}$

FERNANDES, Marcelo dos Santos ${ }^{2}$

RESUMO: Este trabalho teve como objetivo estudar as características morfo-histológicas e funcionais do sistema urinário do sapo Rhinella schineideri frente ao estresse hídrico. Avaliar a função renal através da depuração (clearance) de creatinina, e excretas nitrogenadas como uréia e ácido úrico e íons como sódio, potássio e cloro. Para este estudo foi utilizado 2 grupos experimentais (controle e furosemida), onde o segundo, nome do próprio diurético, foi utilizado. Amostras de sangue e urina foram colhidas com posterior analises. Foram analisados volume e fluxo urinário, concentrações sanguíneas e urinárias e depurações dos solutos citados acima. Em conclusão fica claro a participação de adaptações osmorregulatórias frente à desidratação.

Palavras-chave: Rhinella schneideri. Anatomia e histologia renal. Estresse hídrico osmorregulação. Depuração de creatinina. Furosemida. Co-transporte $\mathrm{Na}^{+}: \mathrm{K}^{+}: 2 \mathrm{Cl}^{-}$.

SUMMARY: This study aimed to analyze the histological and morpho-functional of urinary system of the toad Rhinella schineideri facing water stress. Assess renal function by clearance of creatinine, and nitrogen metabolites as urea and uric acid, and ions like sodium, potassium and chlorine. For this study we used two experimental groups (control and furosemide), where the second one's own name diuretic, was used. Blood and urine were collected and subsequent analysis. We analyzed volume and urinary flow, and blood and urinary clearances of the solutes listed above. In conclusion it is clear participation of adaptations osmoregulation against dehydration.

Keywords: Rhinella schneideri. Anatomy and histology of renal. Water stress osmoregulation. Clearance of creatinine. Furosemide. Co-transport $\mathrm{Na}^{+}: \mathrm{K}^{+}: 2 \mathrm{Cl}^{-}$.

\section{INTRODUÇÃO}

Osmorregulação é um processo em que os animais buscam manter fisiologicamente sua pressão osmótica constante independente de variações do meio externo em que vivem, porém dentro de uma faixa de variação (WERNER,1894).

Anfíbios anuros vivem grande parte de suas vidas na água doce, possuem fluidos corpóreos que são osmoticamente mais concentrados que seu meio e dessa forma ganham constantemente água e perdem $\mathrm{NaCl}$ de seus fluidos corporais para o meio. Assim como na

\footnotetext{
${ }^{1}$ Bacharel em Ciências Biológicas. Departamento de Zoofisiologia. Faculdade de Filosofia, Ciências e Letras. Fundação Educacional de Ituverava. FE/FFCL. e-mail- kleberluissantana@ hotmail.com

${ }^{2}$ Doutor em Fisiologia. Prof. da FE/FFCL. Departamento de Zoofisiologia.
} 
maioria dos vertebrados, eles são osmorreguladores e eliminam o excesso de água em sua urina, que é diluída (RANDALL et al., 2000 ). O NaCl perdido para o meio é recuperado através da alimentação e por transporte ativo realizado por ATPases presentes em seu tegumento (HILDEBRAND, 1995).

O funcionamento geral dos rins, que estão localizados em cada lado da aorta dorsal, é semelhante em todos os anuros, onde a urina é formada por ultrafiltração do sangue realizada pelos capilares glomerulares em seus nefros. Metade ou menos do filtrado formado nessa ultrafiltração, que é muito semelhante ao plasma, é reabsorvido primariamente durante sua passagem pelos segmentos dos nefros. Aproximadamente $90 \%$ dos solutos contidos nesse fluido é reabsorvido produzindo abundante urina diluída, cerca de $0,5 \mathrm{ml} / \mathrm{g} / \mathrm{dia}$ (SHOEMAKER ; NAGY, 1977).

A bexiga é um importante armazenador de água, especialmente para as espécies que vivem em ambientes áridos ou passam por um estresse hídrico, que pode reabsorver água para substituir os fluidos corporais perdidos (DUELLMAN; TRUEB, 1986).

Os rins são mesonéfricos e foram herdados evolutivamente de um sistema excretor semelhante ao de antepassados cordados marinhos, constituído por uma série de túbulos de abertura para o celoma, drenando líquido da cavidade do corpo para o exterior, com reabsorção de solutos valiosos através das paredes dos túbulos.

Os nefros apresentam uma extremidade em forma de funil peritoneal conectado a uma estreita abertura tubular fortemente ciliada. A cápsula de Malpighi é anexado lateralmente a esse túbulo. Segue-se a esse um túbulo convoluto que está dividido em: (A) túbulo proximal e (B) túbulo distal, separados por um (C) segmento de junção equivalente filogeneticamente à alça de Henle observada nos nefros de mamíferos e de aves (GRAY, 1932).

A ausência de uma alça de Henle verdadeira em anfíbios incapacita-os de produção de uma urina hiperosmótica (mais concentrada que o próprio sangue), peculiaridade observada também para os nefros de repteis e algumas aves (SCHMIDT-NIELSEN, 2000).

Os estudos funcionais da porção espessa ascendente da alça de Henle em mamíferos utilizando a técnica de microperfusão em porções isoladas do nefro mostraram ser essa estrutura praticamente impermeáveis à água, mesmo na presença de $\mathrm{ADH}$ e Aldosterona. Neste segmento, ocorre uma reabsorção de $\mathrm{Na}^{+}$na membrana luminal, acoplado a $\mathrm{Cl}^{-}$e $\mathrm{K}^{+}$ através de um co-transporte $\mathrm{Na}^{+}: \mathrm{K}^{+} 2 \mathrm{Cl}^{-}$, o qual utiliza indiretamente a energia gerada pela $\mathrm{Na}^{+}-\mathrm{K}^{+}$-ATPase na membrana basolateral, que se constitui um transporte ativo secundário. A passagem de $\mathrm{Na}^{+}$da luz tubular para o interstício constitui o chamado efeito unitário do 
mecanismo de contracorrente multiplicador (BERNE, 1998).

A porção espessa ascendente da alça de Henle em mamiferos, fundamental ao processo de concentração e diluição urinárias, é o local de ação dos chamados diuréticos de alça, como o furosemida (de nome comercial Lasix) e a bumetanida, os quais, ligando-se ao sítio do íon $\mathrm{Cl}^{-}$, promovem a inibição do co-transportador $\mathrm{Na}^{+}: \mathrm{K}^{-}: 2 \mathrm{Cl}^{-}$(MARTINDALE, 1991; SILVA,1994), redução da reabsorção de água na porção final do túbulo distal e ducto coletor, promovendo assim poliúria.

O furosemida tem sido usado no tratamento de doenças como edemas, insuficiência cardíaca, hipertensão síndrome nefrótica, edema pulmonar, e patologias associadas à hipercalcemia (níveis elevados de cálcio no sangue) e oligúria (que é a ausência ou a diminuição da urina) por insuficiência renal. (MARTINDALE, 1991; SHOENWALD, 1990b).

Apesar da ausência da alça de Henle nos anfíbios, sabe-se que a porção anterior do túbulo distal de seus nefros de anfíbios corresponda filogeneticamente ao ramo espesso ascendente da alça de Henle dos mamíferos, por apresentar co-transportes $\mathrm{Na}^{+}: \mathrm{K}^{+} 2 \mathrm{Cl}^{-}$ sensíveis à furosemida (GREGER, 1985), e suas bexigas à porção final do túbulo distal e ducto coletor do nefro dos mamíferos (OTAKE; ALVES, 2002).

A pergunta que surge diante dessa revisão é como se comportaria o sistema urinário em sapos Rhinella schineideri diante de um estresse hídrico, testando-se inclusive a participação dos co-transportes $\mathrm{Na}^{+}: \mathrm{K}^{+}: 2 \mathrm{Cl}^{-}$sobre a influência do diurético furosemida.

Dessa forma o trabalho teve como objetivo a realização de estudos morfo-histológicos e funcionais do sistema urinário de sapos Rhinella schineideri.

\section{MATERIAL E MÉTODOS}

\section{Animal experimental}

O sapo Rhinella schneideri (WERNE, 1894), membro da família Bufonidae, apresenta o dorso com coloração que vai de castanho claro a escuro com várias glândulas (COCHRAN, 1955) (Figura 1). Quando jovens podem apresentar um dorso negro com algumas faixas brancas. Esta espécie tem atrás do seu tímpano a presença da glândula paratóide que secreta veneno para sua defesa contra predadores. Na tíbia se encontra a glândula paracnêmis. São de hábitos noturnos encontrados em lagos, e em cidades em baixo de postes procurando por presas. O alimento deste animal é constituído geralmente de pequenos insetos como besouros e formigas. Sua reprodução ocorre durante a seca e vai até o período da estação de chuvas de julho a começo de outubro, onde o macho faz a vocalização em lagos e lagoas para atração 
das fêmeas. Logo após a atração ocorre o amplexo que pode ocorrer em ate 40 horas antes da ovoposição. A fêmea deposita aproximadamente 5.000 ovos em uma massa gelatinosa em beiradas de lagos. Os girinos têm os corpos negros que ficam em locais mais rasos da parte do lago e se aglomeram, mas quando ameaçados se escondem na vegetação aquática local (BASTOS et al., 2003).

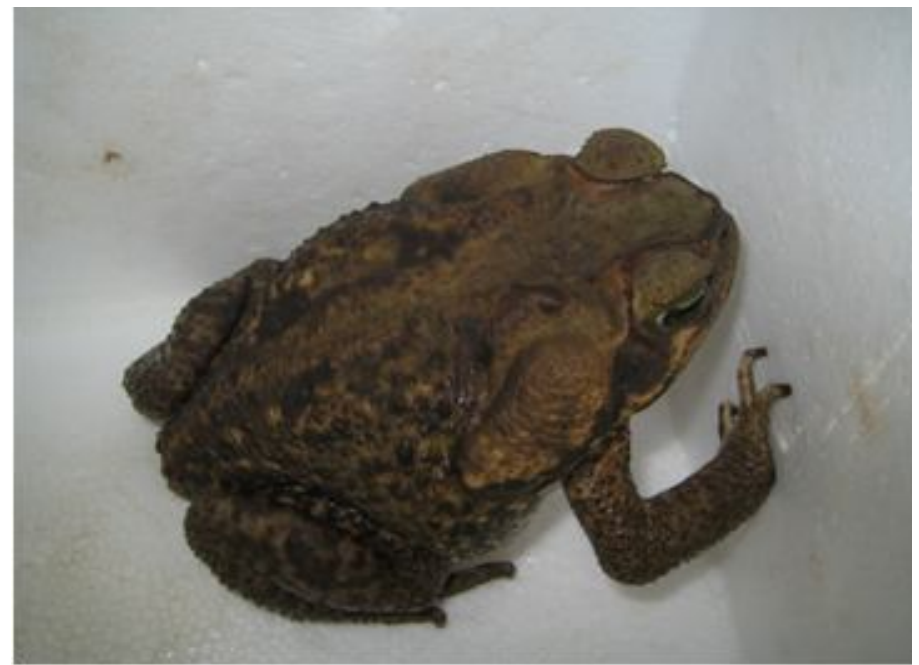

Figura 1: O sapo, Rhinella schneideri Fonte: Werner (1894)

\section{Coleta de animais}

Foram coletados 9 animais em uma lagoa que se localiza no município de Ituverava, nordeste do estado de São Paulo, situado nas coordenadas de $20^{\circ} 20^{\prime} 46.29 " S$ (latitude) e 47²8'8.42"W (longitude) e levados para os laboratórios da FFCLI. Os animais foram coletados manualmente e com o auxílio de um puçá, sendo transportados e armazenados em caixas de 2 litros contendo água e folhas até a execução dos experimentos no laboratório de herpertologia da Faculdade de Filosofia Ciências e Letras de Ituverava (FFCL).

As coletas estiveram de acordo com as exigências do Instituto Brasileiro do Meio Ambiente e dos Recursos Naturais Renováveis (IBAMA) utilizando-se a Licença de Coleta Permanente de Material Zoológico de número de 1015-3.

\section{Aspectos da morfologia e histologia renal}

Para o estudo da morfologia e histologia renal foi escolhido um macho em período reprodutivo com $250 \mathrm{~g}$, tendo sido submetido à eutanásia com xilocaina $5 \%$ através de absorção cutânea direta. Um dos rins foi coletado e conservado em formol 10\%, até ser levado ao laboratório de patologia, onde foram feitos cortes histológicos com micrótomo (Spencer 820), utilizando-se a coloração H.E (Hematoxilina, Eosina). As estruturas renais foram fotografadas por uma câmara fotográfica digital (Sony Cyber, Shot 10.1 Mega pixels, $\mathrm{f}=6.2$ - 
18.6mm 1:3.1-5.6, Sony Lens / optical 3x.) utilizando-se um microscópio (Olympus) em diferentes aumentos.

\section{Aspectos da função renal frente ao estresse hídrico}

Para esses experimentos foram utilizados 8 animais, que após pesados, foram alojados em recipientes de 3 litros enumerados de 1 a 8 , que permaneceram fechados e secos, com pequenas aberturas para a respiração. Tais animais ficaram por 24 horas em restrição a água e alimentos previamente aos experimentos, à temperatura ambiente que foi de $29^{\circ} \mathrm{C}$. Não se preocupou nesse protocolo com os sexos dos animais. Nos sapos dos recipientes de 1 a 4 (grupo controle), receberam em seus estômagos um $1 \mathrm{ml}$ de água destilada a partir de uma sonda de comprimento externo da cânula $0.6 \mathrm{~mm}$, comprimento do tubo $9 \mathrm{~cm}$ (Numero 23 Ref SV*23BLS). Nos sapos dos recipientes de 5 a 8, (grupo furosemida) receberam em seus estômagos, com auxílio de uma pinça, $20 \mathrm{mg}$ do furosemida , acompanhado da injeção de 1 ml de água destilada via sonda. Foi adotado o tempo de duas horas para a realização das medidas. Os animais foram anestesiados com xilocaina $10 \%$ através de absorção cutânea direta e assim eutanasiados. Após incisão abdominal com exposição das vísceras, foram coletados para ambos os grupos experimentais acima descritos amostras de urina e sangue, observando-se também as bexigas quanto à retenção de urina. Foi realizada coleta de urina eliminada pelos animais diretamente nos recipientes e/ou a partir de punção da bexiga urinária. O sangue foi coletado a partir de punção direta do ventrículo cardíaco. As coletas foram feitas com agulhas $25 \times 7$ e seringas de $3 \mathrm{ml}$ separadamente para cada animal. As amostras coletadas foram acondicionadas em tubos de ensaios de vidro sem nenhum anticoagulante para realização das análises. Os estômagos foram abertos para se verificar as condições do diurético fornecido previamente.

\section{Análises laboratoriais}

Foram realizadas análises das concentrações de creatinina, uréia, ácido úrico, sódio, potássio e cloreto a partir de amostras de sangue e urina, para fim de testar a função renal dos animais em experimentação. As análises foram realizadas pelo laboratório Labor Vitae ${ }^{3}$ Igarapava - SP.

\section{Medidas de volume urinário, fluxo urinário e depuração}

Após medidas do volume urinário e cálculo do fluxo urinário dos indivíduos de ambos os grupos experimentais foram comparadas. O fluxo urinário foi calculado dividindo-se a

\footnotetext{
${ }^{3}$ www.laborvitae.com.br
} 
volume urinário pelo tempo de experimento utilizando-se as unidades $\mathrm{ml} / \mathrm{h} / \mathrm{kg}$.

A depuração plasmática (clearance em inglês), depuração plasmática renal ou depuração renal de uma substância representa sua taxa de remoção do sangue para a urina e é calculada multiplicando-se a razão da concentração urinária/sangue de uma substância X $(\mathrm{Ux} / \mathrm{Px})$ pelo fluxo urinário $(\mathrm{Vu})$, expresso em unidades de volume por tempo (geralmente $\mathrm{mL}$ por minuto). Foram calculados as depurações de creatinina, uréia, ácido úrico, sódio, potássio e cloreto para ambos os grupos experimentais e assim comparados.

A creatinina é formada a partir da quebra da creatina pela enzima cretina-quinase, sendo composta por dois aminoácidos, glicina e arginina, nas células de órgãos como fígado, rins e baço, sendo muito importante na contração muscular. A creatina mais a junção de um fosfato (Fosfocreatina) fazem com que haja a ressíntese na molécula de Adenosina trifosfato (LEHNINGER et al., 1995).

Um excelente indicador diagnóstico da função renal é o teste de depuração plasmática de creatinina ou clearance de creatinina que determina a eficiência com que os rins eliminam a creatinina do sangue. A taxa de clearance é expressa em termos de volume de sangue (medido em mililitros) que pode ser limpo de creatinina em 1 minuto. O nível de creatinina no sangue aumenta ocorre quando ocorre a diminuição da taxa de filtração glomerular (TFG) (FINCO 1995; BRUNKER 2005). Como a creatinina é livremente filtrada pelo glomérulo (sendo também secretada pelos túbulos renais em quantidades muito pequenas), sua depuração plasmática é então uma aproximação da TFG, sendo registrada em mililitros por minuto (ml/min) (CUNNINGHAM, 1999).

Apesar da medida da depuração de creatinina endógena ser pouco utilizada na clínica médica, por ser limitada a erros que podem ocorrer na coleta da urina, provou dar resultados muito semelhantes a outras técnicas de depuração de creatinina mais utilizadas como as equações de Cock-Croft- Gault e MDRD (GUSHI, et al., 2004).

Foi adotado nesse trabalho a metodologia da depuração de creatinina endógena, sendo mais adequada para a prática da biologia comparada. O Cálculo da depuração de creatinina endógena é obtido a partir do produto da concentração urinária de creatinina $(\mathrm{mg} / \mathrm{ml})$ pelo volume urinário por minuto $(\mathrm{ml} / \mathrm{min})$, dividido pela concentração sanguínea de creatinina (mg/ml) (BASTOS, et al, 2007) .

\section{Estatísticas}

As análises estatísticas foram obtidas a partir do software PRISMA. As variáveis foram analisadas pelo teste $t$ Student e expressas em média \pm desvio padrão (SEM). Foi considerado significante o valor de $P<0,05$. 


\section{RESULTADOS E DISCUSSÃO}

\section{Anatomia e histologia renal do rim de Rhinella schneideri}

Anatomicamente o rim de Rhinella schneideri analisado apresentou 1g, com medidas de $3.0 \mathrm{~cm}$ no sentido longitudinal, 2.0 no sentido médio-lateral e $0,6 \mathrm{~cm}$ no sentido Antero posterior e superfície externa lobulada castanha brilhante. O rim é acompanhado de um testículo hipertrofiado que mede $2,0 \mathrm{~cm}$ de comprimento e $0.2 \mathrm{~cm}$ de diâmetro, de cor esbranquiçada com um órgão de Bidder anteriormente a esse. O órgão de Bidder é típico da amília bufonidae e representa tecido ovariano atrofiado.

Um ureter emerge do rim e se abre na cloaca. A bexiga urinária de paredes finas posiciona-se ventralmente ao reto e também se abre na cloaca independentemente do ureter.
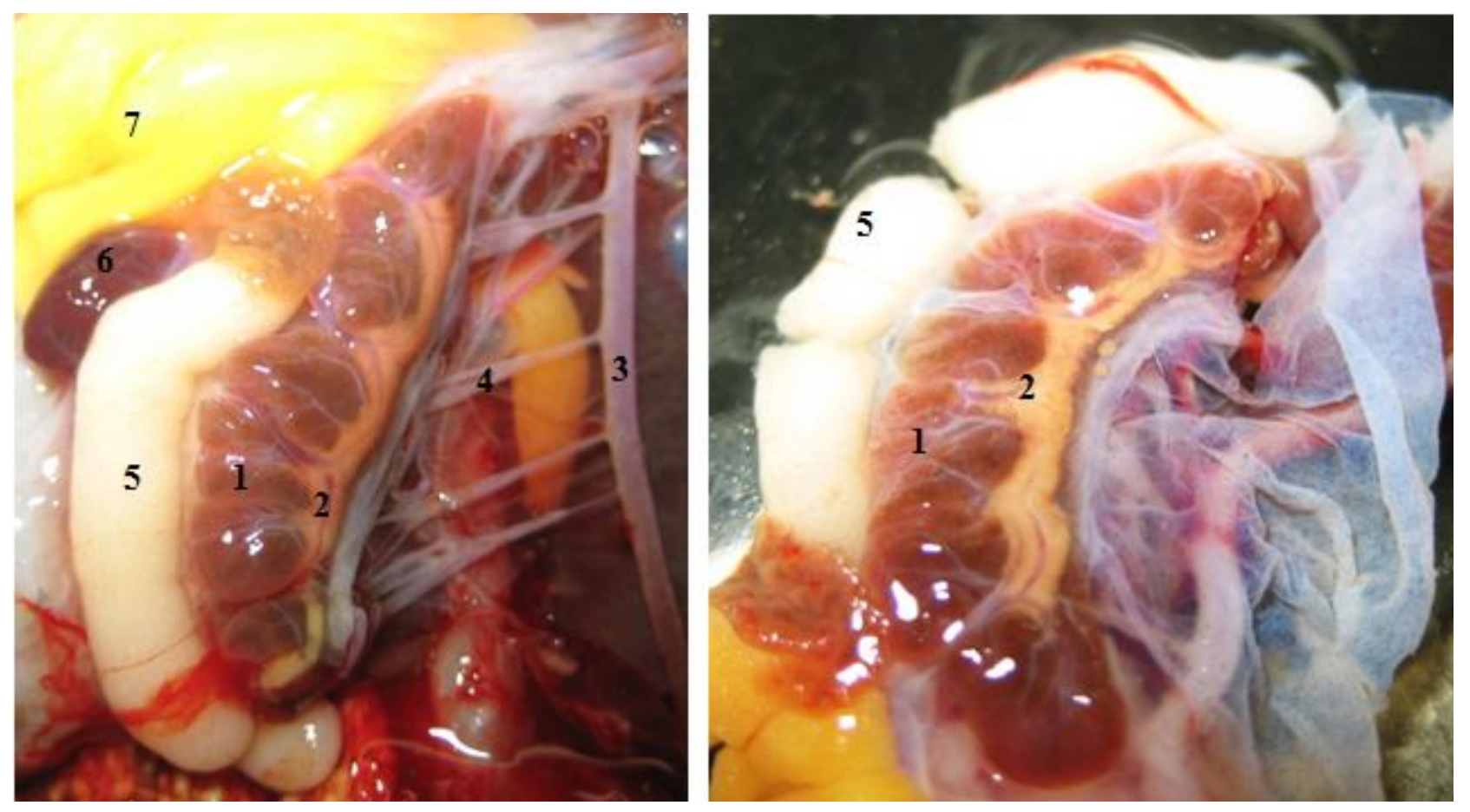

Figura 2. Rim de Rhinella schnederi. 1. rim com lóbulos; 2. glândula adrenal; 3. veia cava posterior; 4.veia renal eferente; 5 . testículo; 6. órgão de Bidder ; 7. tecido adiposo.

Os cortes histológicos mostraram glomérulos associados às cápsulas de Malpighi irrigados por hemácias nucleadas que passam sucessivamente em fileiras e túbulos convolutos (figuras 3 e 4). 

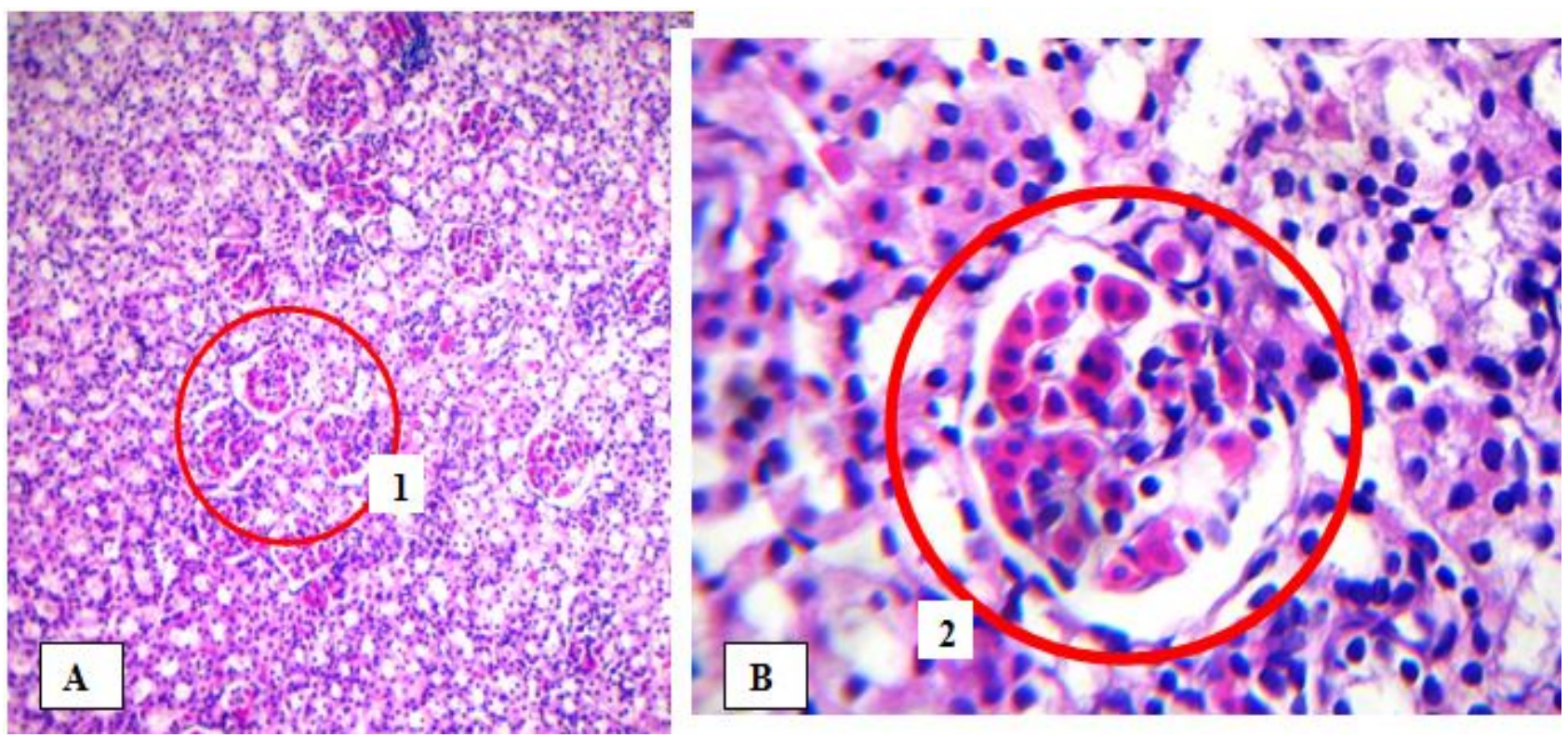

Figura 3. Corte histológico do rim de Rhinella schnederi. A. observa-se em 1 um conjunto de glomérulos (visto em aumento de 40 x.). B. observa-se em 2 um glomérulo em destaque (visto em aumento de $1000 \mathrm{x}$ ).
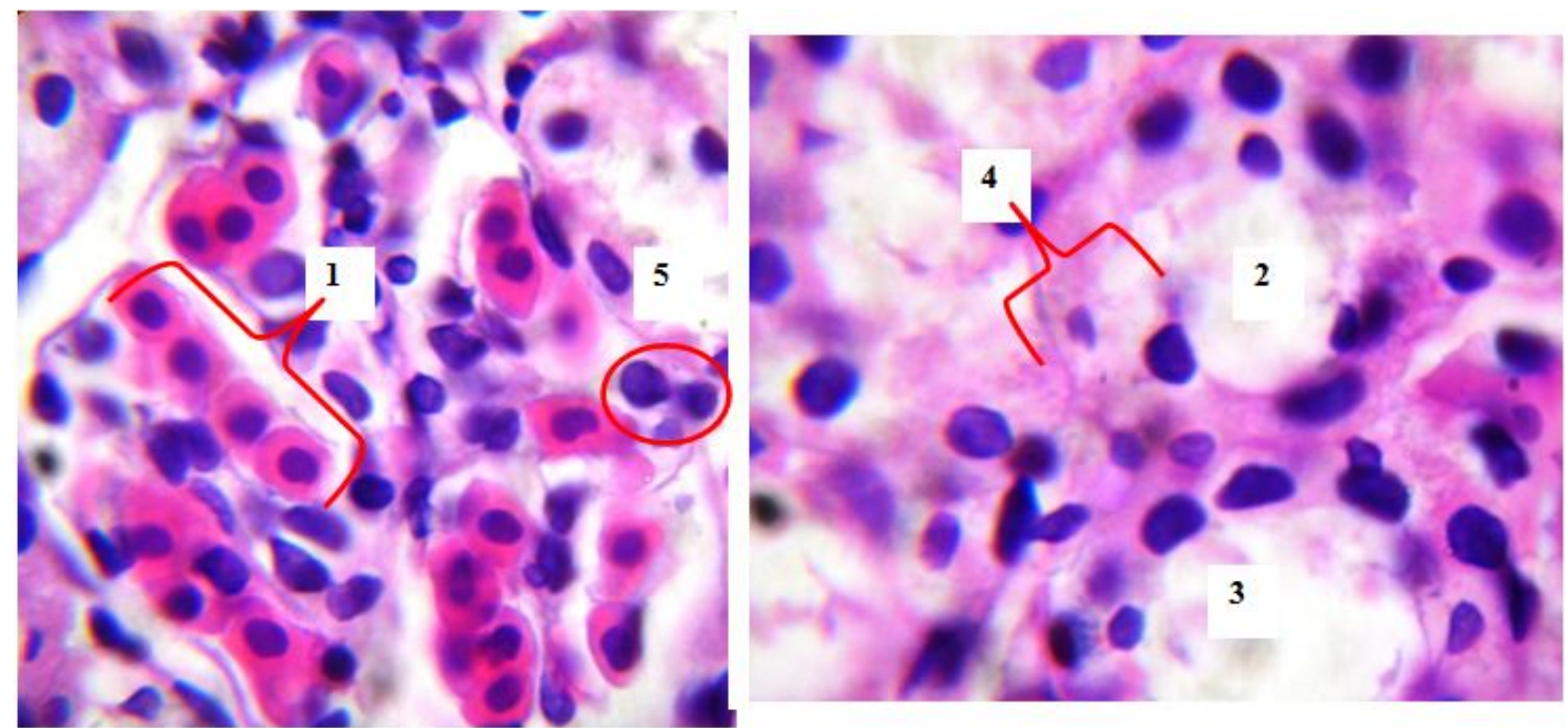

Figura 4. Corte histológico do rim de Rhinella schnederi. 1. Hemácias nucleadas em (visto em aumento de $2.000 \mathrm{x}$ ); 2 e 3 . A luz de dois túbulos proximais (visto em aumento de 2.000 x.); 4. Epitélio pavimentoso uniestratificado de um túbulo proximal; 5. Células mesangliais. 


\section{Aspectos funcionais o rim de Rhinella schneideri}

Análises do volume e fluxo urinários não mostraram diferenças significativas entre os grupos experimentais (Figuras 5 e 6). Diferentemente do que se esperavam os volumes e os fluxos urinários do grupo furosemida não foram maiores do que o controle. Como descrito por Otaka e Alves (2002), o epitélio da bexiga urinária, análogo ao túbulo distal e ao ducto coletor dos mamíferos, pode ter armazenado e reabsorvido o volume de urina extra resultante da ação do furosemida sobre o co-transportador $\mathrm{Na}^{+}: \mathrm{K}^{+}: 2 \mathrm{Cl}^{-}$. Esse processo pode ter sido potencializado pela secreção da arginina vasotoncina (AVT), neuropeptídeo análogo ao hormônio anti-diurético (ADH) liberado pela neuroipófise durante o estresse hídrico (FEDER; BURGGREN, 1992), que aumenta a reabsorção de $\mathrm{NaCl}$ e da água armazenada.

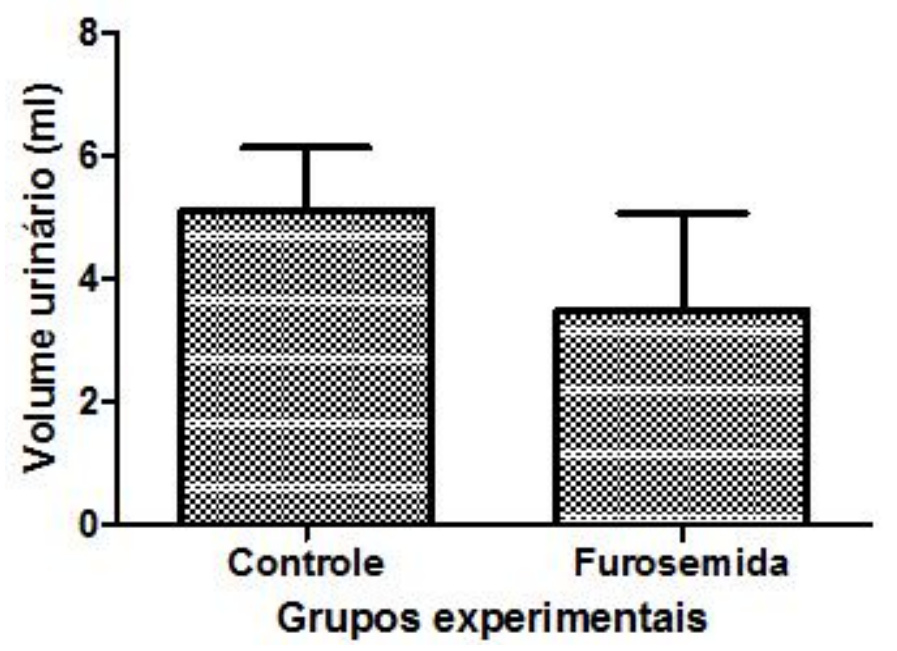

Figura 5. Volume urinário $(\mathrm{ml})$ em Rhinella schneideri, à $29^{\circ} \mathrm{C}$. Média $\pm \mathrm{SEM} ; \mathrm{n}=4$. T-test. $(*)$ representa as diferenças significativas entre o grupo controle e furosemida $(p<0,05)$.

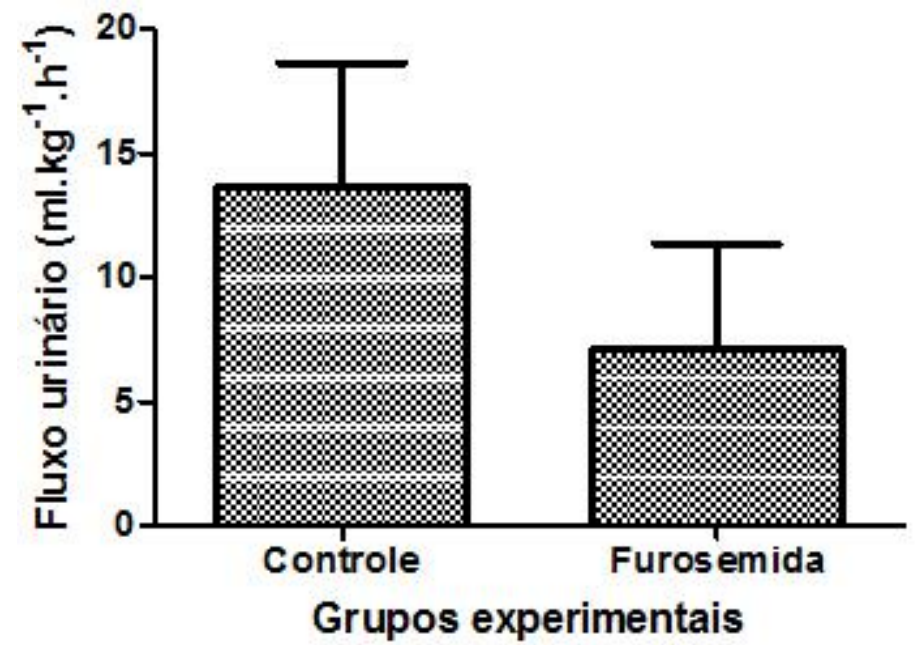

Figura 6. Fluxo urinário $\left(\mathrm{ml} . \mathrm{kg}^{-1} \cdot \mathrm{h}^{-1}\right)$ em Rhinella schneideri, à $29^{\circ} \mathrm{C}$. Média $\pm \mathrm{SEM} ; \mathrm{n}=4$. Ttest. $\left(^{*}\right)$ representa as diferenças significativas entre o grupo controle e furosemida $(p<0,05)$.

As concentrações de sódio e cloreto plasmáticas mostraram-se significativamente 
maiores do que as concentrações urinárias para ambos os grupos experimentais, como podem ser observadas nas figuras 7, 8, 9, 10 corroborando a hipótese da manutenção do equilíbrio osmótico frente a um estresse hídrico. A pergunta que se faz é a seguinte: não teria a furosemida agido ou o sistema buscou contornar a perda de sódio, cloreto e potássio desencadeada pelo diurético? A participação da bexiga urinária teria mascarado a inibição do co-transportador $\mathrm{Na}^{+}: \mathrm{K}^{+}: 2 \mathrm{Cl}^{-}$pelo furosemida, absorvendo os íons e a água? Provavelmente a reabsorção de sódio e cloreto foi aumentada pela ação do AVT corroborando com os dados de Otake e Alves (2002).

A bexiga tem alta capacidade de armazenamento e diluição de urina, principalmente em anuros terrestres que apresentam grandes perdas evaporativas cutâneas, podendo armazenar de 25 a 50\% de sua massa corporal. Foi mostrado que sapos da família bufonidae desidratados podem manter a concentração de seus solutos plasmáticos até que as perdas hídricas sobreponham-se a reserva de água da bexiga e podem ainda tolerar perdas hídricas de 30 a 40\% de suas massas corpóreas (BOUTILIER et al., 1992).

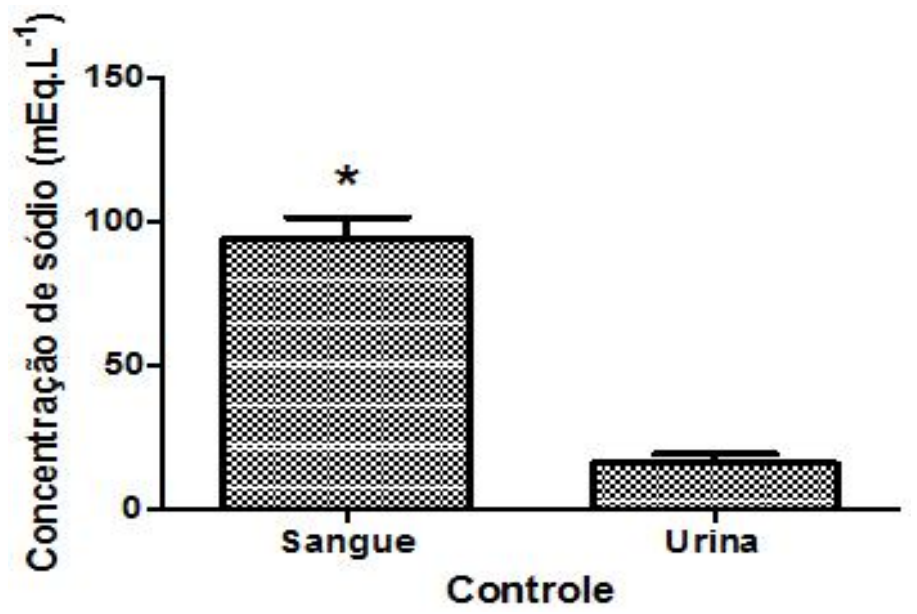

Figura 7. Concentração de sódio $\left(\mathrm{ml}\right.$. dL $\left.{ }^{-1}\right)$ em Rhinella schneideri, a $29^{\circ} \mathrm{C}$. Média $\pm \mathrm{SEM}$; $\mathrm{n}=4$. T-test. $\left.{ }^{*}\right)$ representa as diferenças significativas entre o grupo controle e furosemida $(\mathrm{p}<$ $0,05)$.

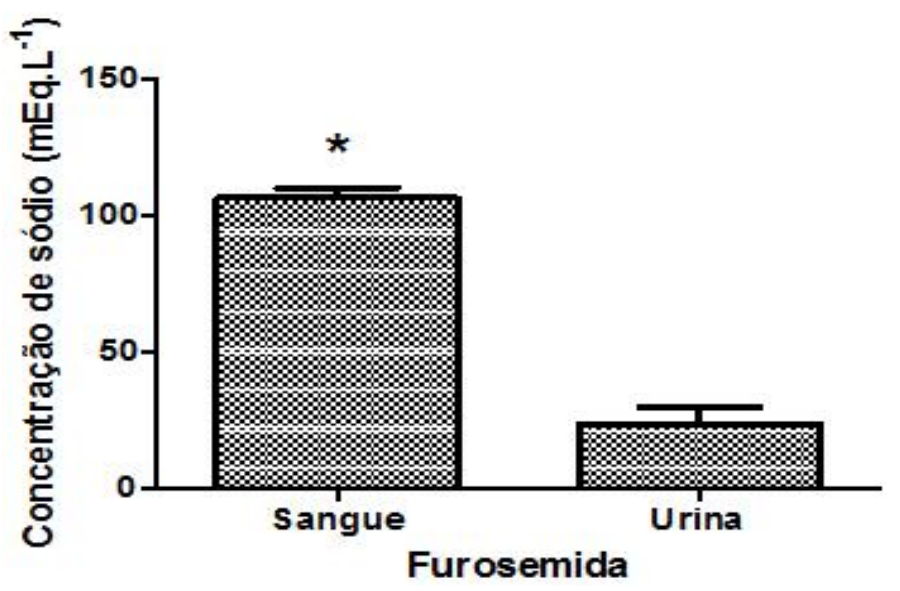


Figura 8. Concentração de sódio $\left(\mathrm{ml} \mathrm{dL}^{-1}\right)$ em Rhinella schneideri, a $29^{\circ} \mathrm{C}$. Média $\pm \mathrm{SEM}$; $\mathrm{n}=4$. T-test. $\left(^{*}\right)$ representa as diferenças significativas entre o grupo controle e furosemida $(\mathrm{p}<$ $0,05)$.

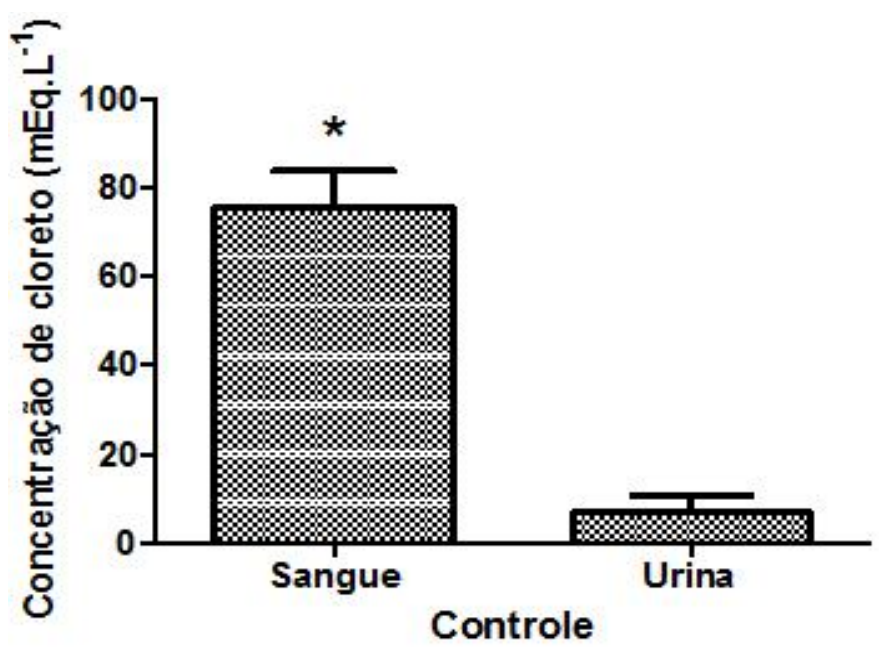

Figura 9. Concentração de cloreto $\left(\mathrm{ml}^{\mathrm{d}} \mathrm{dL}^{-1}\right)$ em Rhinella schneideri, a $29^{\circ} \mathrm{C}$. Média $\pm \mathrm{SEM}$; $\mathrm{n}=4$. T-test. $\left(^{*}\right)$ representa as diferenças significativas entre o grupo controle e furosemida $(\mathrm{p}<$ $0,05)$.

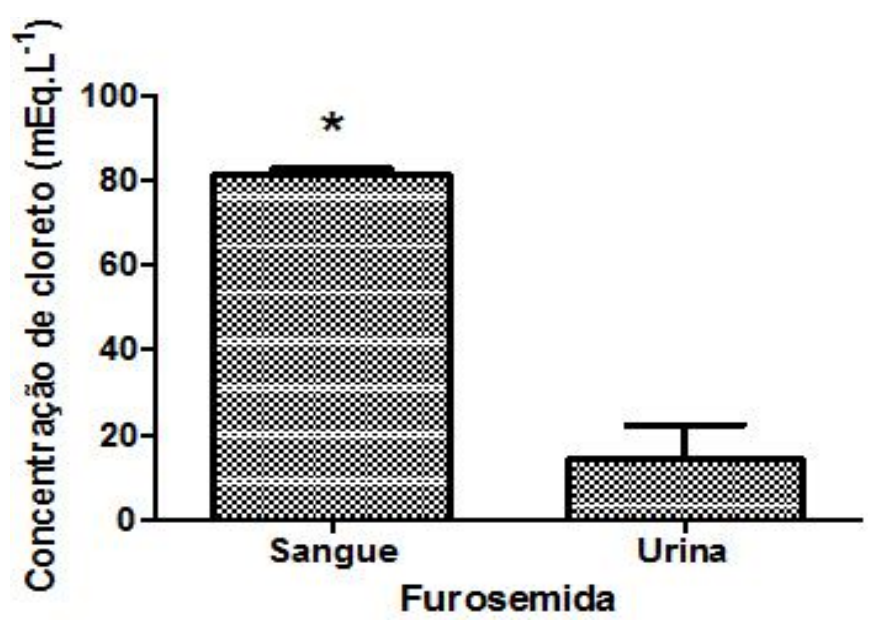

Figura 10. Concentração de cloreto $\left(\mathrm{ml}^{\mathrm{d}} \mathrm{dL}^{-1}\right)$ em Rhinella schneideri, a $29^{\circ} \mathrm{C}$. Média $\pm \mathrm{SEM}$; $\mathrm{n}=4$. T-test. $\left(^{*}\right)$ representa as diferenças significativas entre o grupo controle e furosemida $(\mathrm{p}<$ $0,05)$.

As concentrações de potássio plasmáticas mostraram-se significativamente diferentes das concentrações urinárias apenas para o grupo experimental controle, mesmo mostrando tendência de ser maior no plasma no grupo furosemida, como podem ser notadas nas figuras 11 e 12. Esses dados corroboram com a ação da furosemida que levaria a uma maior excreção de potássio. 


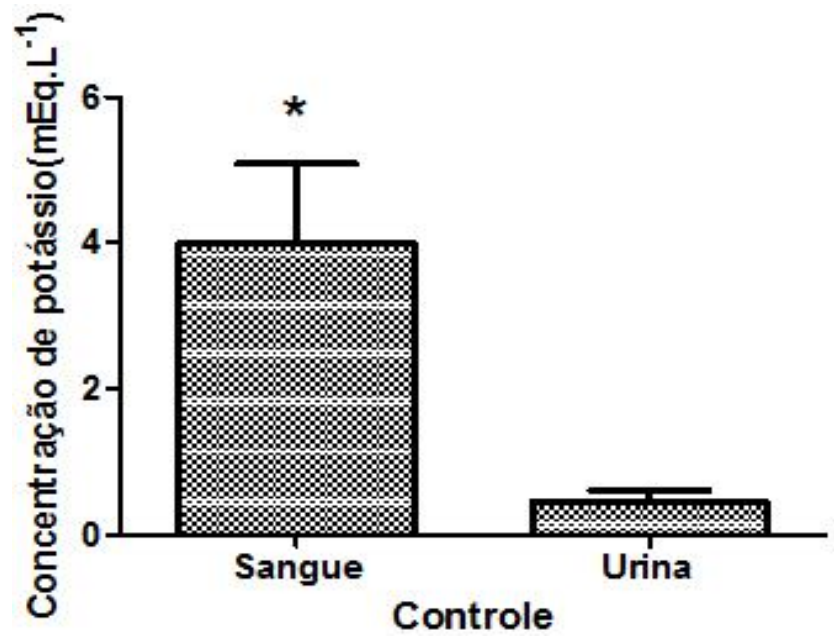

Figura 11. Concentração de potássio $\left(\mathrm{ml} . \mathrm{dL}^{-1}\right)$ em Rhinella schneideri, a $29^{\circ} \mathrm{C}$. Média \pm $\mathrm{SEM} ; \mathrm{n}=4$. T-test. (*) representa as diferenças significativas entre o grupo controle e furosemida $(\mathrm{p}<0,05)$.

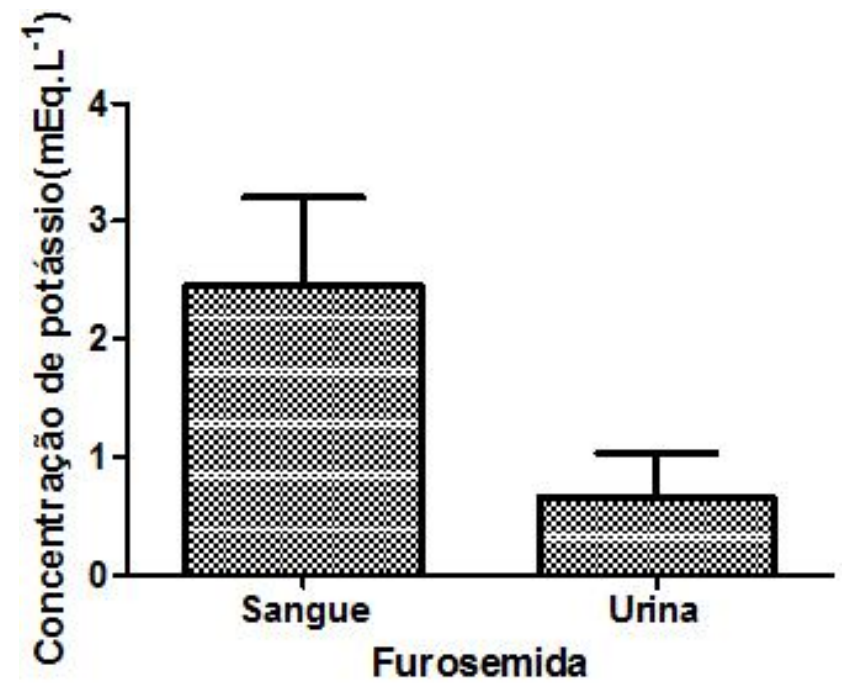

Figura 12. Concentração de potássio $\left(\mathrm{ml} . \mathrm{dL}^{-1}\right)$ em Rhinella schneideri, a $29^{\circ} \mathrm{C}$. Média \pm SEM; $n=4$. T-test. $(*)$ representa as diferenças significativas entre o grupo controle e furosemida $(\mathrm{p}<0,05)$.

A depuração de creatinina, que expressa a taxa de filtração glomerular (TFG) não mostrou alterações significativas entre os grupos experimentais, como pode ser visto na figura 13, levando-nos a inferir que a taxa de filtração glomerular não tenha sido alterada pelo uso da furosemida. 


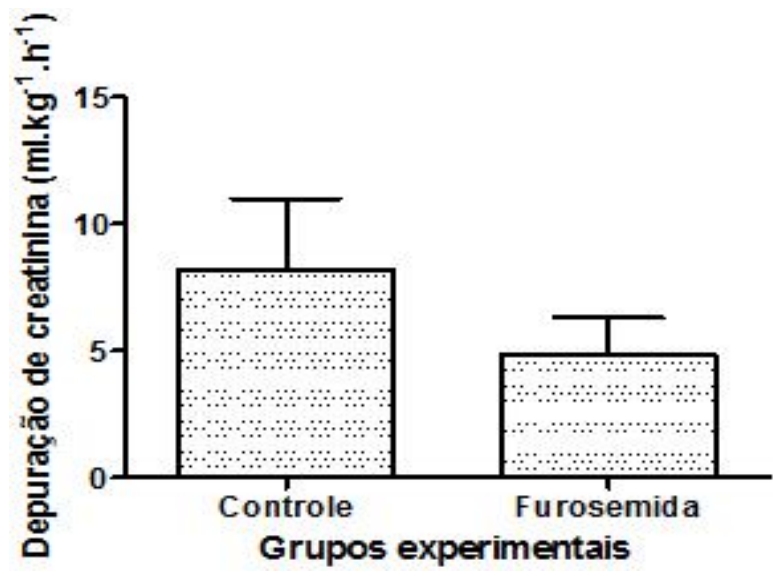

Figura 13. Depuração de creatinina $\left(\mathrm{ml} \mathrm{Kg}{ }^{-1} \cdot \mathrm{h}^{-1}\right)$ em Rhinella schneideri, a $29^{\circ} \mathrm{C}$. Média \pm SEM; $\mathrm{n}=4$. T-test. $(*)$ representa as diferenças significativas entre o grupo controle e furosemida $(\mathrm{p}<0,05)$.

Anfíbios podem apresentar drásticas alterações da TGF frente à desidratação, podendo reduzi-la em até 20 vezes. A maioria dos anfíbios produz em média $20,8 \mathrm{ml} \cdot \mathrm{kg}^{-1} \cdot \mathrm{h}^{-1}$ quando estão em contato com água do meio. A TFG de Bufo marinus mostrou alterações após 1 hora sem contato com a água, o chegando a reduzir praticamente a zero de 8 a 10 de desidratação (PARSON et al., 1993).

Os valores da depuração de creatinina obtidos nesse trabalho são relativamente abaixo daqueles de anuros hidratados, variando de 19 a $58 \mathrm{ml} \cdot \mathrm{kg}^{-1} \cdot \mathrm{h}^{-1}$, corroborando com a hipoótese de manutenção osmótica frente a desidratação. O AVT também tem efeito redutor sobre a TFG de anfíbios (BENTLEY, 1971).

A depuração de sódio, potássio e cloreto não mostraram alterações significativas entre os grupos experimentais, como pode ser visto na figura 14, 15, e 16, levando-nos a inferir que a furosemida não tenha interferido nos processos de excreção desses íons.

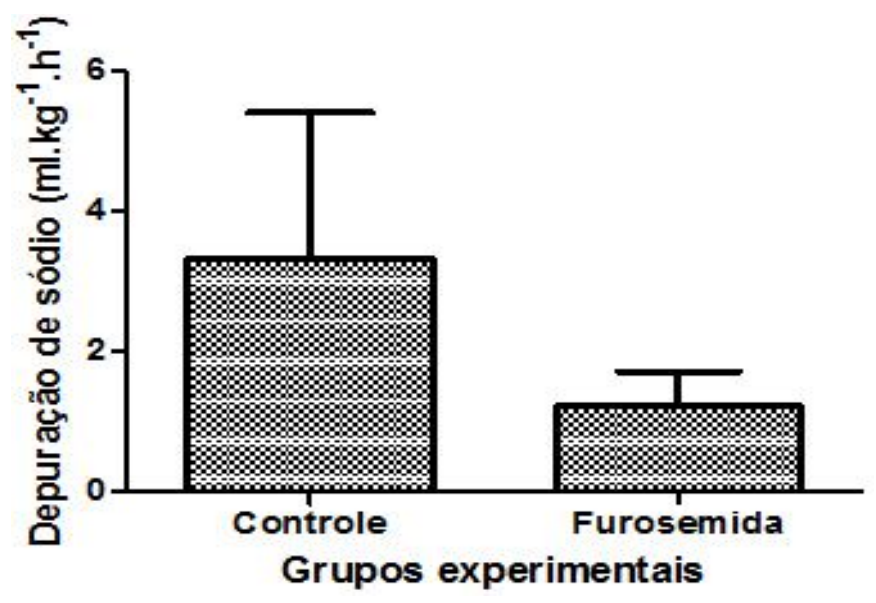

Figura 14. Depuração de sódio $\left(\mathrm{ml} . \mathrm{kg}^{-1} \cdot \mathrm{h}^{-1}\right)$ em Rhinella schneideri, a $29^{\circ} \mathrm{C}$. Média $\pm \mathrm{SEM}$; $\mathrm{n}=4$. T-test. $\left.{ }^{*}\right)$ representa as diferenças significativas entre o grupo controle e furosemida $(\mathrm{p}<$ $0,05)$. 


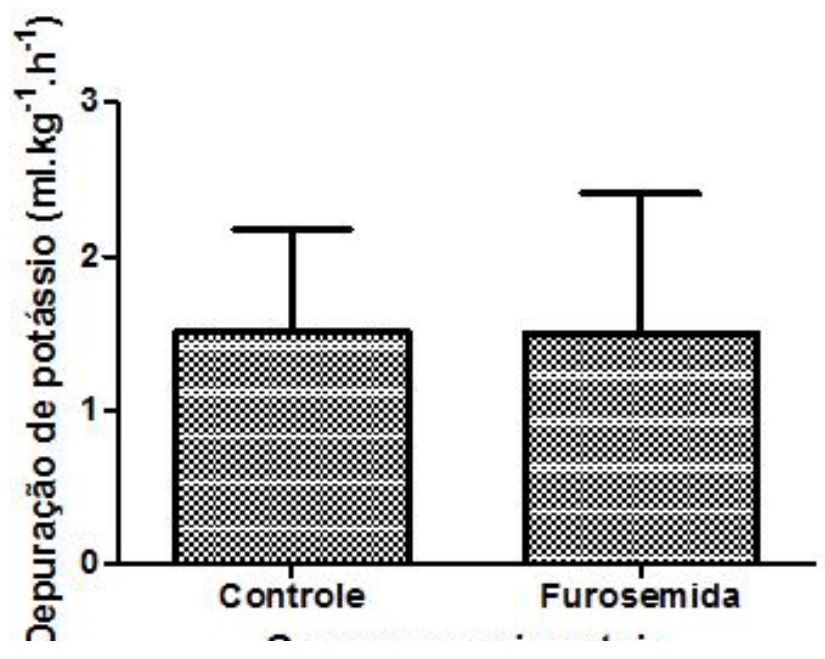

Figura15. Depuração de potássio $\left(\mathrm{ml} . \mathrm{kg}^{-1} \cdot \mathrm{h}^{-1}\right)$ em Rhinella schneideri, a $29^{\circ} \mathrm{C}$. Média \pm SEM; $\mathrm{n}=4$. T-test. (*) representa as diferenças significativas entre o grupo controle $\mathrm{e}$ furosemida $(\mathrm{p}<0,05)$.

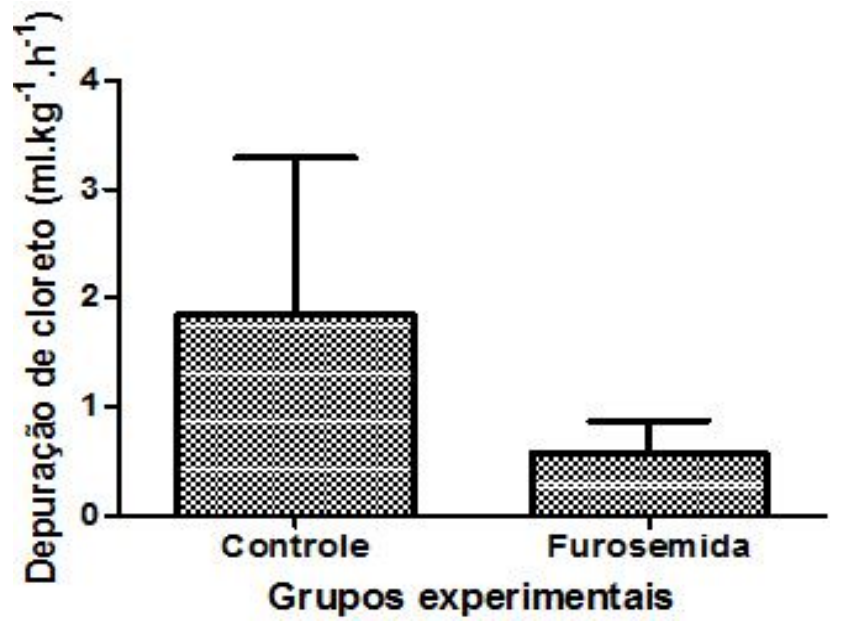

Figura16. Depuração de cloreto $\left(\mathrm{ml} . \mathrm{kg}^{-1} \cdot \mathrm{h}^{-1}\right)$ em Rhinella schneideri, a $29^{\circ} \mathrm{C}$. Média $\pm \mathrm{SEM}$; $\mathrm{n}=4$. T-test. $(*)$ representa as diferenças significativas entre o grupo controle e furosemida $(\mathrm{p}<$ $0,05)$.

A depuração de uréia e ácido úrico também não mostraram alterações significativas entre os grupos experimentais, como pode ser visto na figura 17 e 18 . 


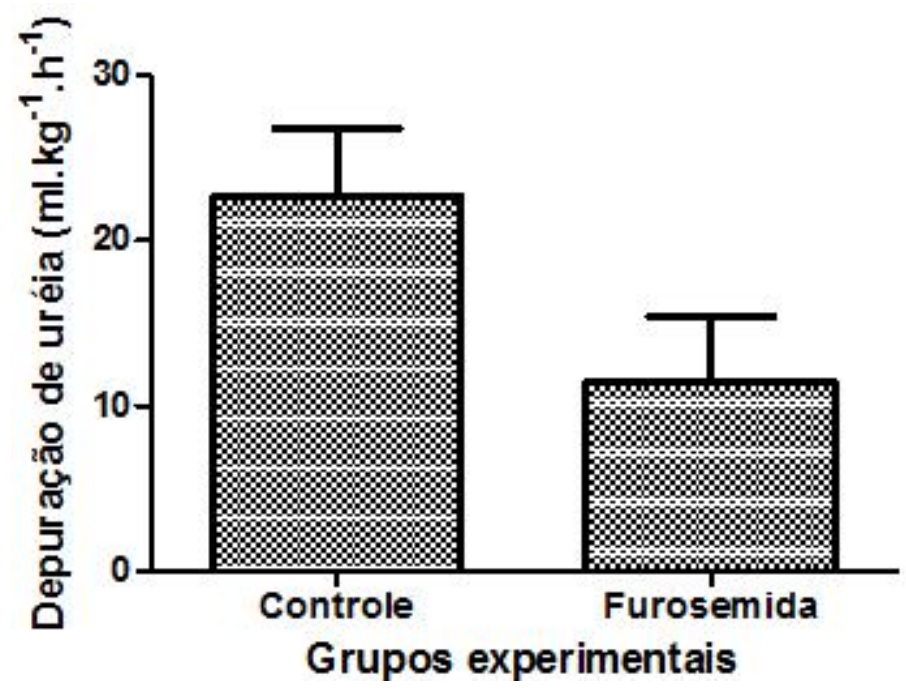

Figura 17. Depuração de uréia $\left(\mathrm{ml} . \mathrm{kg}^{-1} \cdot \mathrm{h}^{-1}\right)$ em Rhinella schneideri, a $29^{\circ} \mathrm{C}$. Média $\pm \mathrm{SEM}$; $\mathrm{n}=4$. T-test. ( $)$ representa as diferenças significativas entre o grupo controle e furosemida $\left(\mathrm{p}<^{<}\right.$ $0,05)$.

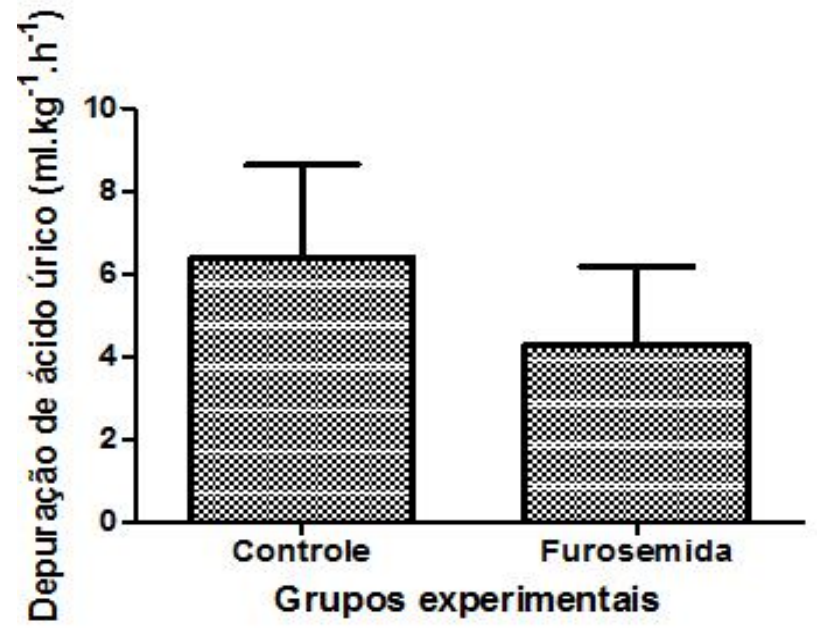

Figura 18. Depuração de ácido úrico $\left(\mathrm{ml} . \mathrm{kg}^{-1} \cdot \mathrm{h}^{-1}\right)$ em Rhinella schneideri, a $29^{\circ} \mathrm{C}$. Média \pm $\mathrm{SEM} ; \mathrm{n}=4$. T-test. (*) representa as diferenças significativas entre o grupo controle e furosemida' 0,05$)$.

A uréia é proveniente da metabolização hepática a partir da amônia, sendo menos tóxica e o produto nitrogenado prevalente da excreção de anfíbios adultos (GUPTA et al., 1977). Essa característica pode ser notada nas figuras 19 e 20 em ambos os grupos experimentais. Apesar da concentração urinária de uréia parecer mais elevada do que a plasmática, não mostraram diferenças estatísticas significativas. 


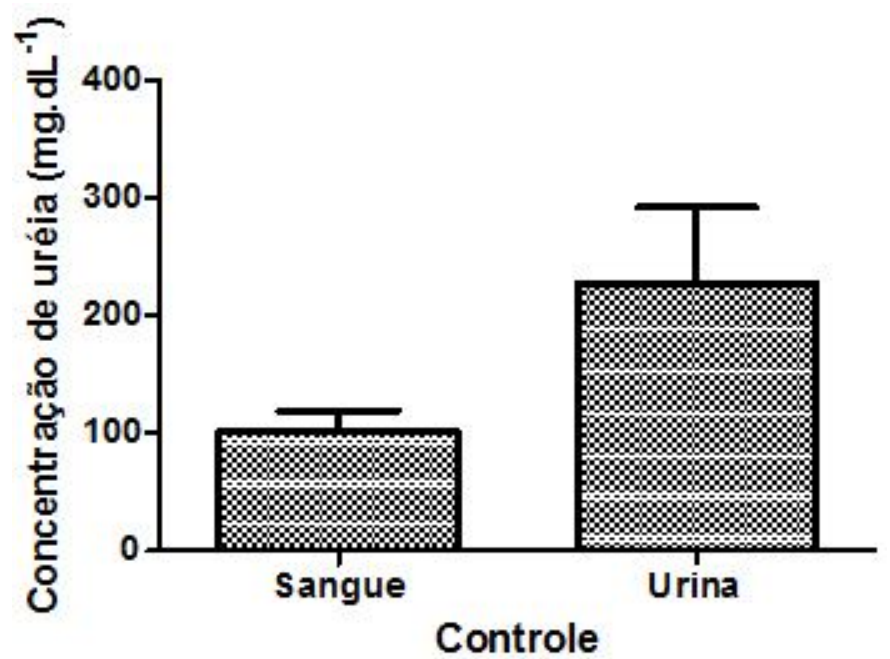

Figura 19. Concentração de uréia $\left(\mathrm{ml} . \mathrm{dL}^{-1}\right)$ em Rhinella schneideri, a $29^{\circ} \mathrm{C}$. Média \pm SEM; n=4. T-test. $(*)$ representa as diferenças significativas entre o grupo controle e furosemida $(\mathrm{p}<0,05)$.

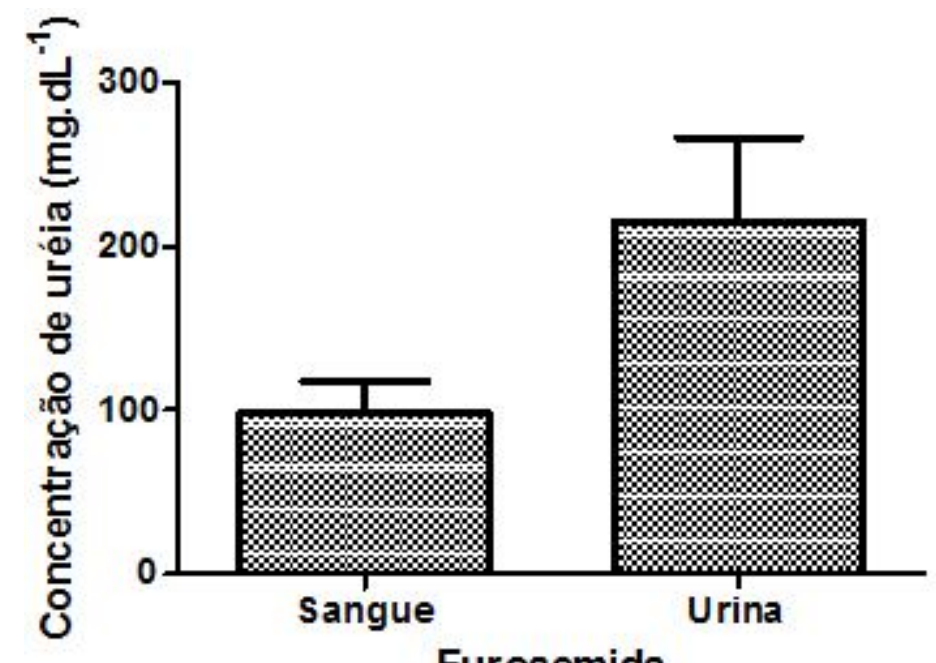

Furosemida

Figura 20. Concentração de uréia $\left(\mathrm{ml} . \mathrm{dL}^{-1}\right)$ em Rhinella schneideri, a $29^{\circ} \mathrm{C}$. Média \pm $\mathrm{SEM} ; \mathrm{n}=4$. T-test. $\left(^{*}\right)$ representa as diferenças significativas entre o grupo controle e furosemida $(\mathrm{p}<0,05)$.

A excreção de ácido úrico na urina mostrou-se menor do que a de uréia como observado geralmente para anfíbios anuros (Duellman e Trueb, 1986) como podemos ver nas figuras 21 e 22. As concentrações de ácido úrico plasmáticas mostraram-se significativamente diferentes das concentrações urinárias apenas para o grupo controle, corroborando com os dados da depuração de tal excreta nitrogenada. 


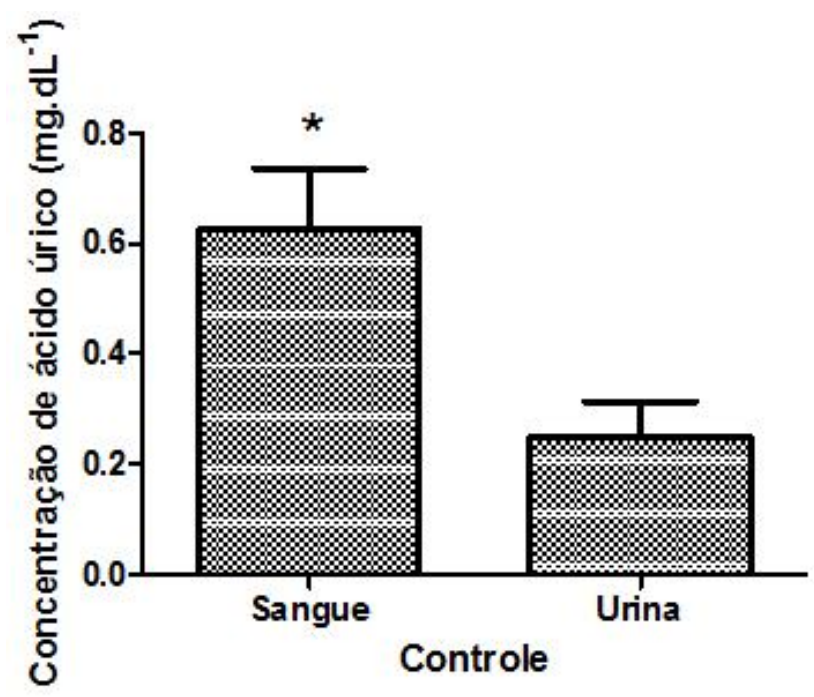

Figura 21. Concentração de acido úrico $\left(\mathrm{ml} . \mathrm{dL}^{-1}\right)$ em Rhinella schneideri, a $29^{\circ} \mathrm{C}$. Média $\pm \mathrm{SEM} ; \mathrm{n}=4$. T-test. $\left.{ }^{*}\right)$ representa as diferenças significativas entre o grupo controle e furosemida $(\mathrm{p}<0,05)$.

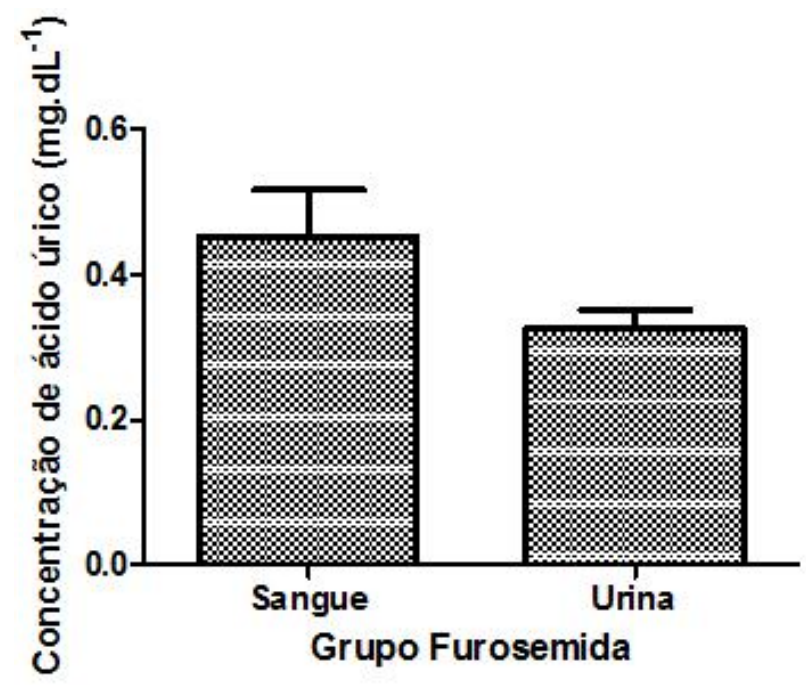

Figura 22. Concentração de ácido úrico $\left(\mathrm{ml} . \mathrm{dL}^{-1}\right)$ em Rhinella schneideri, a $29^{\circ} \mathrm{C}$. Média $\pm \mathrm{SEM} ; \mathrm{n}=4$. T-test. $\left(^{*}\right)$ representa as diferenças significativas entre o grupo controle e furosemida $(\mathrm{p}<0,05)$.

\section{CONCLUSÃO}

Os resultados levam-nos a concluir que Rhinella schneideri em prol de sua homeostase foi capaz de desencadear respostas fisiológicas adaptativas osmorregulatórias frente ao estresse hídrico em ambos os grupos experimentais. O que não ficou claro foi a ação do diurético furosemida, necessitando de mais estudos. 


\section{REFERÊNCIAS}

BASTOS, R. M. et al. Avaliação da função renal em pacientes com creatinina sérica normal. Rev. APS, v.110, n.1, 2007.

BASTOS, R. P.; LIMA, L. P.; PASQUALI, M. S. Sapos, rãs e pererecas: desvendando o segredo dos anfíbios. Goiânia: R. P. BASTOS, 2003. 12p.

BENTLEY, P. J. Endocrines and osmoregulation. New York, Heidelberg, Berlin: SpringerVerlag, 1971.

BERNE, R. M. Fisiologia. 4.ed. Rio de Janeiro: Guanabara Koogan, 1998.1034p.

BOUTILIER, R.G.; STIFFLER, D.F.; TOEWS, D.P. Exchange of respiratory gases, ions, and water in amphibious and aquatic amphibians. In: FEDER, M.E.; BURGGREN, W.W..

Environmental physiology of the amphibians. Chicago: The University of Chicago Press, 1992. p.81-124.

BRUNKER J. Protein losing nephropaty. Comp. Cont. Educ. Pract.Vet. v.27, p.686-695, 2005.

COCHRAN, D. M. Frogs of sooutheastern Brazil. Bull. U.S. Nat. Mus., n. 206, p. 1-423, 1955.

CUNNINGHAM, J. G. Tratado de fisiologia veterinária. 2. ed.Rio de Janeiro: Guanabara Koogan, 1999.528p.

DUELLMAN, W.E. ; TRUEB, L. Biology of amphibians. New York: McGraw- Hill : 1986. $670 \mathrm{pp}$.

FEDER,M.E; BURGGREN, W.W. Environmental physiology of the amphibians. Chicago: University of Chicago Press, 1992.

FINCO D. Urinary protein loss. In: OSBORNE C.A.; FFINCO D.R. (eds). Canine and feline nephrology and urology. Baltimore: Lea and Febiger, 1995. p.211-215.

GRAY, P. Memoirs: the development of the amphibian kidney. The development of the kidney of triton vulgaris and a comparison of this form with rana temporaria. Quarterly Journal of

Microscopical Science, v. s2-75, p.425-465, 1932.

GREGER, R. Ion transport mechanisms in thick ascending limb of Henle's loop of mammalian nephron. Physiological Reviews, v.65, p.760-793, 1985.

GUSHI , A.A.et al. Avaliações da filtração glomerular pela depuração de creatinina, equações MDRD e Cockcroft-Gault são semelhantes em receptores de transplante renal. J Bras Nefrol v. 26, n.3, p. 165-169, 2004.

GUPTA, B. L.et al. Transport of ions and water in animals. London: Academic Press, 1977

HILDEBRAND, M. Análise da estrutura dos vertebrados. São Paulo: Atheneu, 1995. $700 \mathrm{p}$. 
LEHNINGER, A. L.; NELSON, D. L.; CON, M. M. Princípios de bioquímica. Trad. de Arnaldo Antonio Simões, Wilson Roberto Navega Lodi. 2.ed. São Paulo: Sarvier, 1995. 839p.

MARTINDALE, W. H. The extra pharmacopoeia. 30. ed. London: Pharmaceutical Press, 1991. p. 815-818.

OTAKE, A.H; ALVES. M.J.Q.F. Efeito do extrato aquoso de tese-sangrias[ Cuphea mesostemon (Koehme) Lourt] sobre o fluxo de água, medido em bexiga urinária de sapo in vitro. REV.BRAS.PL.MED. Botucatu, v.4, n.2, p.19-23, 2002.

PARSONS, R.H. et al. Regulation of pelvic patch water flow in Bufo marinus: Role of bladdervolume and ANG II. Am. J. Physiol. v.264, p.R1260-R1265, 1993.

SCHMIDT- NIELSEN. Fisiologia animal. adaptação e meio ambiente. 6. ed. Rio de Janeiro: Guanabara Koogan, 2000.

THRALL, M. A. et al. Hematologia e bioquímica veterinária. São Paulo: Roca, 2007. 582p. 
